\title{
HARDENING BAJA AISI 1045 MENGGUNAKAN GEL ALOE VERA SEBAGAI MEDIA PENDINGIN
}

\author{
Eko Budiyanto ${ }^{1}$, Moch. Agus Choiron², Djarot B. Darmadi ${ }^{3}$ \\ ${ }^{1}$ Teknik Mesin Universitas Muhammadiyah Metro, Ki Hajar Dewantara, 15A - Metro (34111), \\ Lampung-Indonesia \\ 2,3Teknik Mesin Universitas Brawijaya, MT Haryono, 167- Malang (65145), Indonesia \\ E-mail : eko_budiyanto99@yahoo.com
}

\begin{abstract}
Quenching is a cooling method of heat treatment for metal hardening. Quenching refers to the process of rapidly cooling metal parts from the austenitizing or solution treating temperature, typically from within the range of 815 to $970{ }^{\circ} \mathrm{C}$ for steel. The selection of a quenchant medium depends on the hardenability of the particular alloy, the section thickness and shape involved, and the cooling rates to achieve the desired microstructure. The liquid quenchants of oil is commonly used in industrial manufacture. But, oil is not environmental. The aim of this research research is to find new quenchant for change oil as quenchant to more environmental. Gel aloe vera is purposed for it. The material used in this study is AISI 1045 steel. Cooling curve and cooling rate is measured by finite element model, ANSYS APDL 14.5. True experimental is done to view microstructure and measure hardness of steel. Simulation result shown that gel aloe vera has almost similar cooling curve and cooling rate with oil. Microstructure result of steel for gel aloe vera as quenchant is martensite in surface, bainite in center, and pearlite in between surface and center. Hardness number of steel for gel aloe vera as quenchant is $189.63 \mathrm{HVN}$ in surface, 182.566 HVN in center, and 162.866 HVN in between surface and center. By simulation and true experimental analisys concluded that gel aloe vera has opportunities to change oil as quenchant for hardening process.
\end{abstract}

Keywords: hardening, Steel AISI 1045, gel aloe vera, cooling curve, cooling rate.

\section{PENDAHULUAN}

Semakin meningkatnya permintaan pasar terhadap penggunaan logam yang diiringi dengan meningkatnya penjualan kendaraan bermotor di Indonesia [1], mendorong para pelaku industri untuk menghasilkan produk logam yang sesuai dengan kebutuhan konsumen. Research, design, dan manufaktur terus dilakukan guna meningkatkan kualitas produk dengan biaya yang kompetitif. Beberapa permintaan konsumen terhadap kebutuhan logam diantaranya adalah logam yang kuat dan tahan terhadap keausan.

Untuk memperbaiki sifat logam agar tahan terhadap keausan, dapat dilakukan dengan meningkatkan kekerasan logam. Salah satu metode heat treatment yang digunakan untuk meningkatkan kekerasan logam adalah dengan cara hardening, yaitu proses pemanasan baja sampai suhu di daerah atau di atas daerah kritis disusul dengan pendinginan yang cepat atau disebut quench. Logam yang telah dipanaskan pada suhu di atas suhu rekristalisasi didinginkan dengan cara dicelupkan pada media pendingin seperti air atau pada cairan tertentu. Keberhasilan dari hardening pada umumnya diartikan dengan tercapainya mikrostruktur, kekerasan, kekuatan, dan ketangguhan yang diharapkan serta dapat meminimalisir residual stress, distorsi, dan kemungkinan crack [2].

Adie (2013), meneliti pengaruh media pendingin pada heat treatment terhadap struktur mikro dan sifat mekanik friction wedge baja AISI 1340. Variasi yang digunakan adalah media pendingin air, oli SAE 20W, dan pendinginan udara pada temperatur austenitisasi $840{ }^{\circ} \mathrm{C}$ dan waktu tahan 20 menit. Hasilnya, heat treatment dengan media pendingin oli SAE $20 \mathrm{~W}$ menunjukkan performa yang paling optimum dengan menghasilkan struktur mikro berupa martensite dan retained austenite.

Yang and Zhu (2013) menggunakan Finite Elemen Model (FEM) untuk mensimulasikan proses quenching pada Aluminium dan penurunan residual stress selama cold stretching process. Hasilnya menunjukkan 
bahwa pemodelan quenching ini bisa untuk memprediksikan residual stress dengan ketelitian tinggi [3].

Berdasarkan beberapa penelitian tersebut diatas, media pendingin berperan penting terhadap hasil hardening. Pemilihan media pendingin mempengaruhi kekerasan suatu bahan, ketebalan dan bentuk juga ikut terlibat, dan cooling rate dibutuhkan untuk mencapai mikrostruktur dan jumlah martensite yang diharapkan [1]. Salah satu dari beberapa faktor pemilihan media pendingin quenching syaratnya adalah media pendingin yang ramah lingkungan. Permasalahan yang dihadapi saat ini adalah beberapa produsen logam menggunakan oli sebagai media pendingin dengan alasan nilai cooling rate yang sesuai untuk pembentukan jumlah martensite. Penemuan media pendingin baru yang lebih ramah lingkungan tentunya diharapkan dapat menggantikan peran oli sebagai media pendingin. Gel aloe vera yang didapat dari tanaman lidah buaya (aloe vera) memiliki kandungan air 95.51\% dengan densitas 9146 $\mathrm{kg} / \mathrm{m}^{3}$ namun memiliki viscositas $58.0 \mathrm{cp}$. Dengan mempertimbangkan kandungan air, densitas, dan viscositas, maka gel aloe vera dapat diusulkan sebagai media pendingin pada proses quenching baja. Keuntungan jika menggunakan gel aloe vera sebagai media pendingin adalah lebih ramah lingkungan dibandingkan dengan media pendingin oli.

Dari ulasan tersebut diatas, maka perlu dilakukan penelitian proses quenching baja dengan gel aloe vera sebagai media pendingin. Agar dapat menggantikan peran oli sebagai media pendingin, gel aloe vera harus memiliki nilai cooling rate yang mendekati nilai cooling rate pada oli karena pembentukan jumlah martensite pada logam sangat dipengaruhi oleh nilai cooling rate. Untuk mempermudah dalam memvisualisasikan distribusi temperatur dan siklus thermal/cooling curve serta laju pendinginan (cooling rate) yang terjadi pada proses quenching, maka diperlukan sebuah alat bantu simulasi. Salah satu cara yang dapat digunakan adalah dengan bantuan Finite Element Model, yaitu dengan menghitung dan memodelkan perpindahan panas tersebut menggunakan simulasi komputer.

\section{METODOLOGI PENELITIAN}

Metode penelitian yang digunakan dalam peneltian ini adalah perpaduan eksperimental semu dan eksperimental nyata. Eksperimental semu dengan simulasi komputer menggunakan software yang berbasis metode elemen hingga. Eksperimental nyata dilakukan sebagai validasi dan melihat struktur mikro serta kekerasan spesimen uji pada media pendingin gel aloe vera.

\section{Variabel penelitian}

- Variabel bebas

Variabel bebas dalam penelitian ini adalah media pendingin dan temperatur media pendingin. Variabel ini dapat dilihat pada Tabel 1. Sedangkan dimensi spesimen uji dapat dilihat pada Gambar 1.

Tabel 1. Variabel bebas dan jumlah percobaan

\begin{tabular}{|c|c|c|}
\hline \multirow{2}{*}{ Trial } & \multirow{2}{*}{$\begin{array}{c}\text { Media } \\
\text { Pendingin }\end{array}$} & $\begin{array}{c}\text { Temperatur } \\
\text { Media } \\
\text { Pendingin }\left({ }^{\circ} \mathrm{C}\right)\end{array}$ \\
\hline 1 & \multirow{3}{*}{ gel aloe vera } & 25 \\
& & 45 \\
\hline 2 & \multirow{3}{*}{ Air } & 65 \\
\hline 3 & & 25 \\
\hline 4 & \multirow{3}{*}{ Oli SAE 20} & 45 \\
\hline 5 & & 65 \\
\hline 6 & & 25 \\
\hline 7 & & 45 \\
\hline 8 & & 65 \\
\hline 9
\end{tabular}

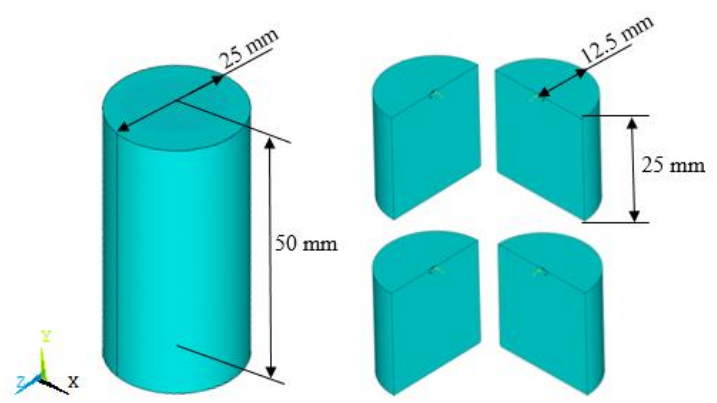

Gambar 1. Bentuk serta dimensi spesimen uji dan pemodelan elemen hingga

- Variabel Terikat

Dalam penelitian ini yang menjadi variabel terikat adalah thermal gradient, thermal flux, siklus thermal/cooling curve, dan laju pendinginan (cooling rate) dari proses quenching. 
- Variabel Terkontrol

- Diameter dan panjang spesimen 25 $\mathrm{mm}$ dan $50 \mathrm{~mm}$,

- Initial condition $900^{\circ} \mathrm{C}$,

- Jenis material Baja AISI 1045.

\section{Data Material}

- Material yang digunakan pada pemodelan ini adalah Steel AISI 1045 dengan menggunakan material isotropik.

- Media pendingin gel aloe vera, air, oli SAE 20.

Tabel 2. Data thermal properties material dan media pendingin

\begin{tabular}{|c|c|c|}
\hline Material & $\begin{array}{l}\text { Thermal } \\
\text { properties }\end{array}$ & Value \\
\hline \multirow{3}{*}{$\begin{array}{c}\text { Steel } \\
\text { AISI } \\
1045^{*}\end{array}$} & Density $(\rho)$ & $7870 \mathrm{~kg} / \mathrm{m}^{3}$ \\
\hline & $\begin{array}{c}\text { Thermal } \\
\text { conductivity (k) }\end{array}$ & $51,9 \mathrm{~W} / \mathrm{m} . \mathrm{K}$ \\
\hline & Spesific heat (C) & $486 \mathrm{~J} / \mathrm{kg} . \mathrm{K}$ \\
\hline \multirow{3}{*}{ Air $^{* *}$} & Density $(\rho)$ & $998 \mathrm{~kg} / \mathrm{m}^{3}$ \\
\hline & $\begin{array}{c}\text { Convective } \\
\text { coefficient (h) }\end{array}$ & $\mathrm{N} / \mathrm{m}^{2} . \mathrm{K}$ \\
\hline & viscosity $(\mu)$ & $1 \mathrm{cp}$ \\
\hline \multirow{3}{*}{$\begin{array}{c}\text { Oli } \\
\text { SAE20** }\end{array}$} & Density $(\rho)$ & $885.7 \mathrm{~kg} / \mathrm{m}^{3}$ \\
\hline & $\begin{array}{c}\text { Convective } \\
\text { coefficient }(h)\end{array}$ & $62 \mathrm{~W} / \mathrm{m}^{2} . \mathrm{K}$ \\
\hline & viscosity $(\mu)$ & $140 \mathrm{cp}$ \\
\hline \multirow{3}{*}{$\begin{array}{l}\text { Gel aloe } \\
\text { vera }^{* * *}\end{array}$} & Density $(\rho)$ & $914.6 \mathrm{~kg} / \mathrm{m}^{3}$ \\
\hline & $\begin{array}{c}\text { Convective } \\
\text { coefficient (h) }\end{array}$ & $68 \mathrm{~W} / \mathrm{m}^{2} . \mathrm{K}$ \\
\hline & cosit & $58.0 \mathrm{cp}$ \\
\hline
\end{tabular}

\section{Meshing dan Load Condition}

Meshing adalah proses membagi obyek yang semula adalah elemen tak terhingga (infinite) menjadi elemen-elemen tertentu dengan jumlah yang berhingga (finite). Dalam penelitian ini digunakan meshing secara otomatis dengan jenis elemen explicit dan tipe elemen brick 8 node dengan ukuran $0.13 \mathrm{~mm}$. Jumlah node 51771 dan jumlah element 35832. Pembebanan convection thermal diberikan pada seluruh permukaan spesimen dan input initial condition $900^{\circ} \mathrm{C}$. Gambar 2 menunjukkan meshing yang digunakan pada penelitian ini.

\section{Eksperimental}

Eksperimental adalah sebagai validasi untuk melihat mikrostruktur dan kekerasan dari logam sesudah dilakukan proses hardening. Langkah-langkahnya adalah;
1. Memotong logam menjadi bentuk spesimen dengan diameter $25 \mathrm{~mm}$ dan panjang 50 $\mathrm{mm}$.

2. Spesimen dipanaskan dalam tungku induksi sampai pada suhu $900^{\circ} \mathrm{C}$.

3. Holding time selama 30 menit agar temperatur pada spesimen merata $900^{\circ} \mathrm{C}$.

4. Dicelupkan kedalam gel aloe vera.

5. Setelah dingin spesimen dipotong dan dibelah menjadi 4 kemudian di lakukan pengamatan struktur mikro dan kekerasan pada spesimen menggunakan photo mikro dan digital microhardness tester.

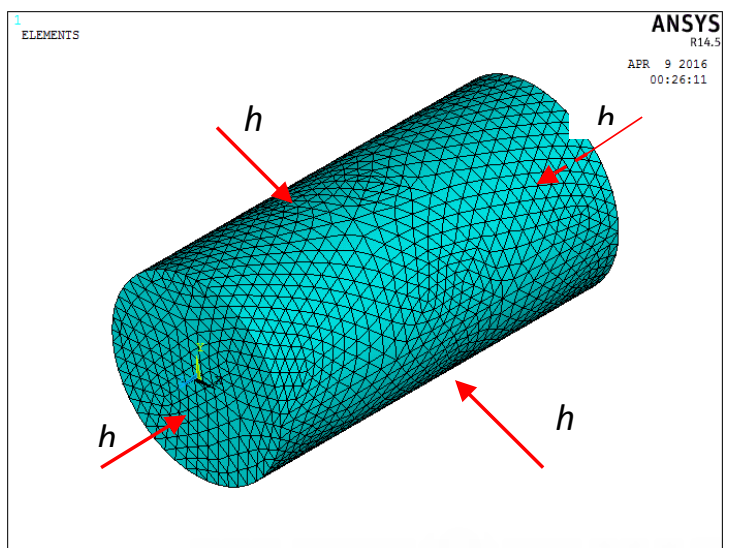

Gambar 2. Meshing pada shoftware MEH

Titik pengamatan struktur mikro dan kekerasan dapat dilihat pada Gambar 3.

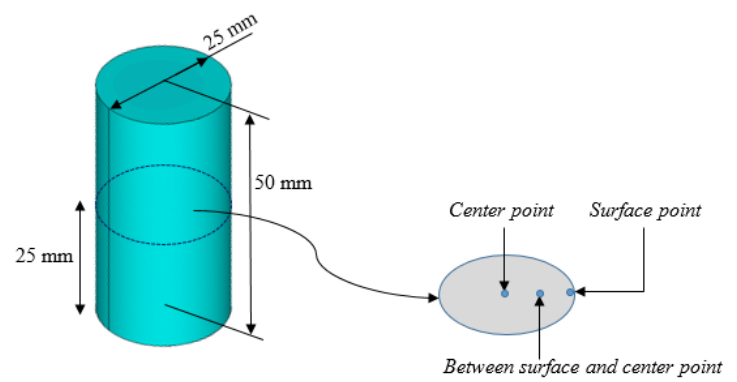

Gambar 3. Titik pengamatan struktur mikro dan uji kekerasan

\section{HASIL DAN PEMBAHASAN}

Beberapa data hasil simulasi proses quenching dengan media pendingin gel aloe vera, air, dan oli sebagai media pendingin adalah thermal gradient, thermal flux, dan grafik siklus thermal/cooling curve. Data dari grafik siklus thermal/cooling curve dapat membantu menemukan nilai cooling rate pada masingmasing media pendingin. Data dari grafik siklus 
thermal/cooling curve dapat membantu menemukan nilai cooling rate pada masingmasing media pendingin.

Data hasil simulasi berupa contour plot untuk thermal gradient pada media pendingin gel aloe vera ditunjukkan pada Gambar 4. Sedangkan contour plot untuk thermal gradient pada media pendingin air ditunjukkan pada Gambar 5 dan contour plot untuk thermal gradient pada media pendingin oli ditunjukkan pada Gambar 6.

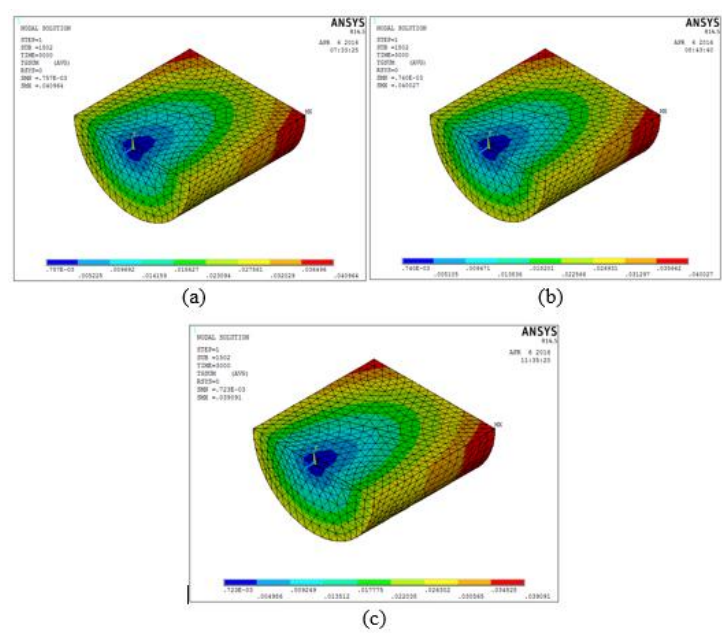

Gambar 4. Thermal gradient media pendingin gel aloe vera, (a) temperatur media pendingin $25^{\circ} \mathrm{C}$, (b) $45^{\circ} \mathrm{C}$, (c) $65^{\circ} \mathrm{C}$.

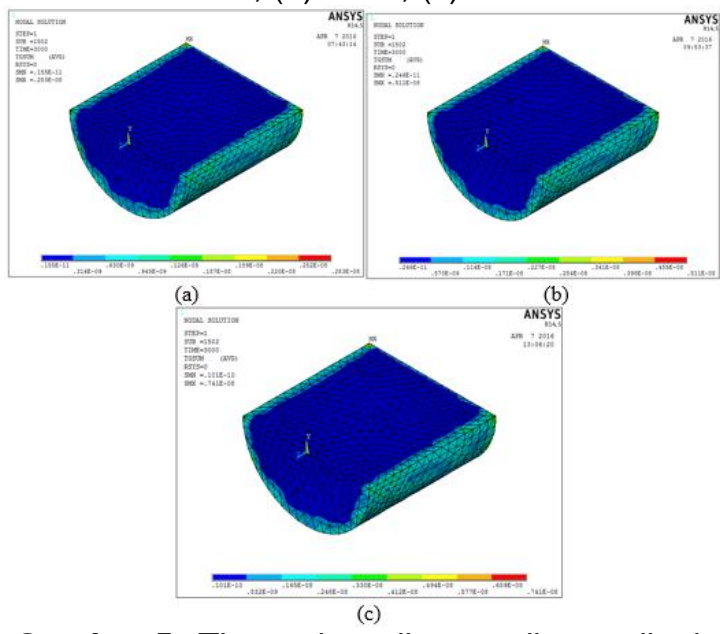

Gambar 5. Thermal gradient media pendingin air, (a) temperatur media pendingin $25^{\circ} \mathrm{C}$, (b)

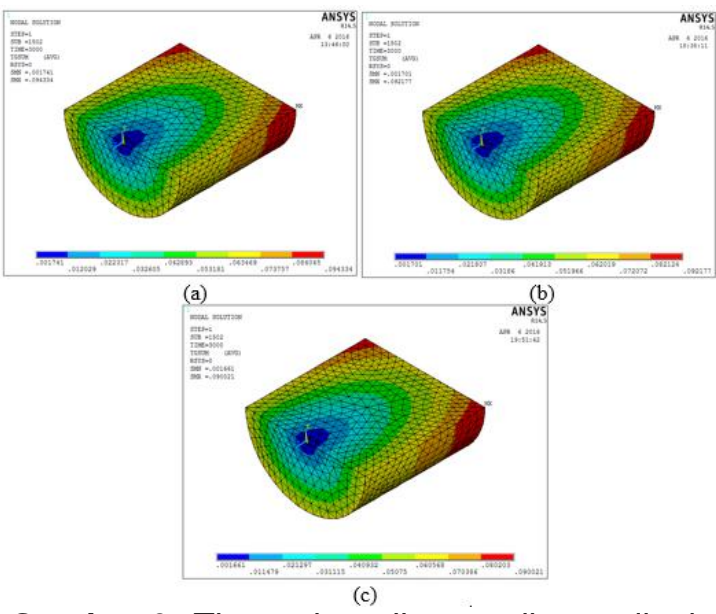

Gambar 6. Thermal gradient media pendingin oli, (a) temperatur media pendingin $25^{\circ} \mathrm{C}$, (b) $45^{\circ} \mathrm{C}$, (c) $65^{\circ} \mathrm{C}$.

Nilai thermal gradient maksimal yang tertinggi untuk keseluruhan media pendingin dicapai oleh proses quenching pada media pendingin oli dengan temperatur media pendingin $25^{\circ} \mathrm{C}$ dengan nilai thermal gradient $4.44463 \mathrm{~K} / \mathrm{m}$, sedangkan nilai thermal gradient maksimal yang terendah untuk keseluruhan media pendingin dicapai oleh proses quenching dengan media pendingin air dengan temperatur media pendingin $25^{\circ} \mathrm{C}$ dengan nilai thermal gradient $0.105 \times 10^{-9} \mathrm{~K} / \mathrm{m}$. Pada media pendingin gel aloe vera dan oli, semakin rendah temperatur media pendingin akan semakin tinggi nilai thermal gradient dan semakin tinggi temperatur media pendingin akan semakin rendah nilai thermal gradient. Sedangkan pada media pendingin air berlaku sebaliknya, semakin rendah temperatur media pendingin akan semakin rendah nilai thermal gradient dan semakin tinggi temperatur media pendingin akan semakin tinggi nilai thermal gradient.

Data hasil simulasi berupa contour plot untuk thermal flux pada media pendingin gel aloe vera ditunjukkan pada Gambar 7 . Sedangkan contour plot untuk thermal flux pada media pendingin air ditunjukkan pada Gambar 8 dan contour plot untuk thermal flux pada media pendingin oli ditunjukkan pada Gambar 9. 


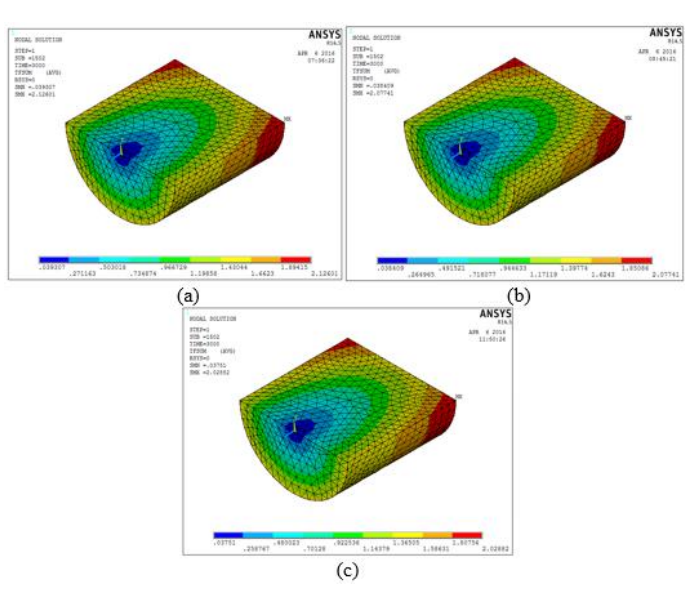

Gambar 7. Thermal flux media pendingin gel aloe vera, (a) temperatur media pendingin $25^{\circ} \mathrm{C}$, (b) $45^{\circ} \mathrm{C}$, (c) $65^{\circ} \mathrm{C}$.

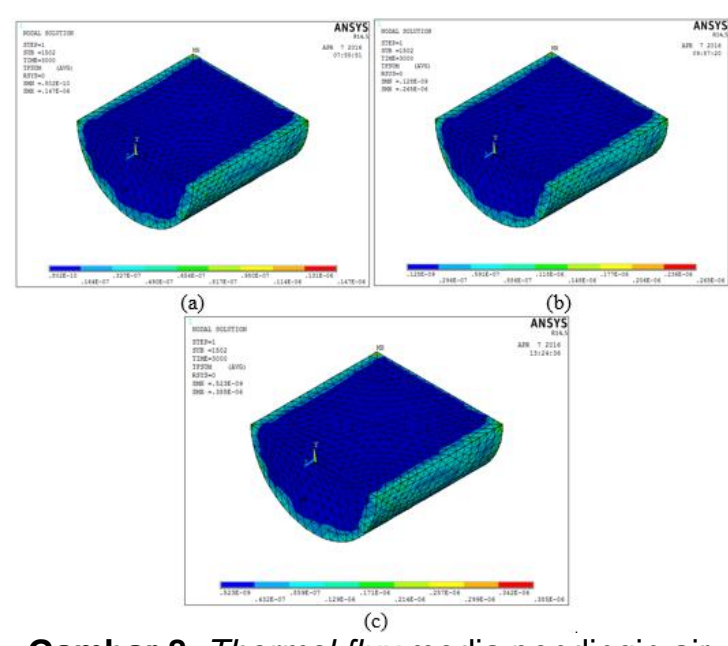

Gambar 8. Thermal flux media pendingin air,

(a) temperatur media pendingin $25^{\circ} \mathrm{C}$, (b) $45^{\circ} \mathrm{C}$, (c) $65^{\circ} \mathrm{C}$.

Nilai thermal flux maksimal yang tertinggi untuk keseluruhan media pendingin dicapai oleh proses quenching pada media pendingin oli dengan temperatur media pendingin $25^{\circ} \mathrm{C}$ dengan nilai thermal flux 4.89591 Watt, sedangkan nilai thermal flux maksimal yang terendah untuk keseluruhan media pendingin dicapai oleh proses quenching dengan media pendingin air dengan temperatur media pendingin $25^{\circ} \mathrm{C}$ dengan nilai thermal flux $0.147 \times 10^{-6}$ Watt. Pada media pendingin gel aloe vera dan oli, semakin rendah temperatur media pendingin akan semakin tinggi nilai thermal flux dan semakin tinggi temperatur media pendingin akan semakin rendah nilai thermal flux. Sedangkan pada media pendingin air berlaku sebaliknya, semakin rendah temperatur media pendingin akan semakin rendah nilai thermal flux dan semakin tinggi temperatur media pendingin akan semakin tinggi nilai thermal flux.

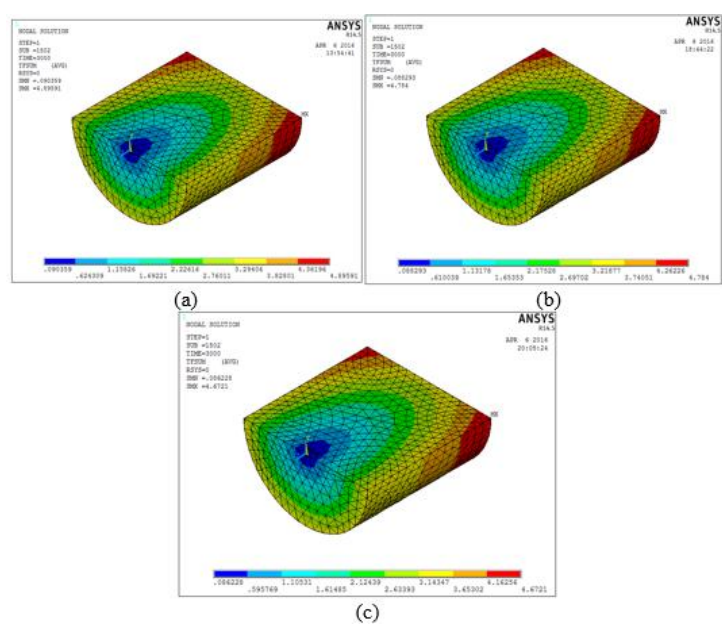

Gambar 9. Thermal flux media pendingin oli,

(a) temperatur media pendingin $25^{\circ} \mathrm{C}$, (b) $45^{\circ} \mathrm{C}$, (c) $65^{\circ} \mathrm{C}$.

Pada saat proses quenching berlangsung terjadi suatu siklus thermal dalam hal ini adalah penurunan temperatur (cooling curve). Penurunan temperatur yang terjadi pada saat proses quenching keseluruhan variabel uji diambil pada pusat center spesimen $(\mathrm{x}=0 \mathrm{~mm}$, node 10$)$, surface $(x=12.5 \mathrm{~mm}$, node 2$)$, dan antara surface dengan center $(x=6.25 \mathrm{~mm}$, node 533). Titik pengambilan data cooling curve pada spesimen uji dapat dilihat pada Gambar 10.

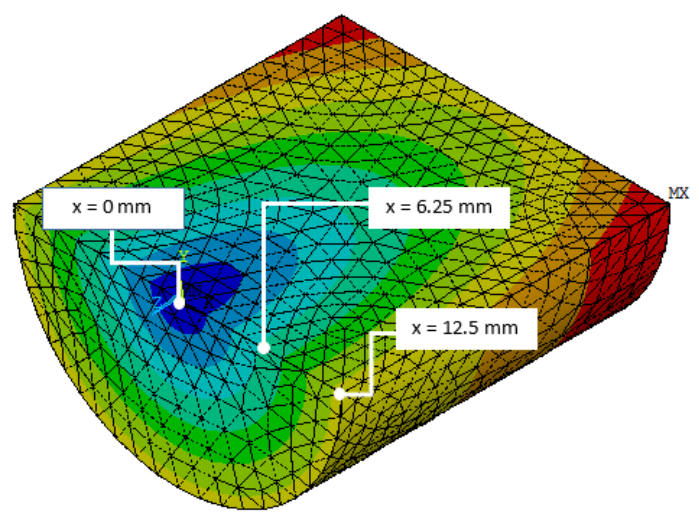

Gambar 10. Titik pengambilan data cooling curve pada spesimen uji. 


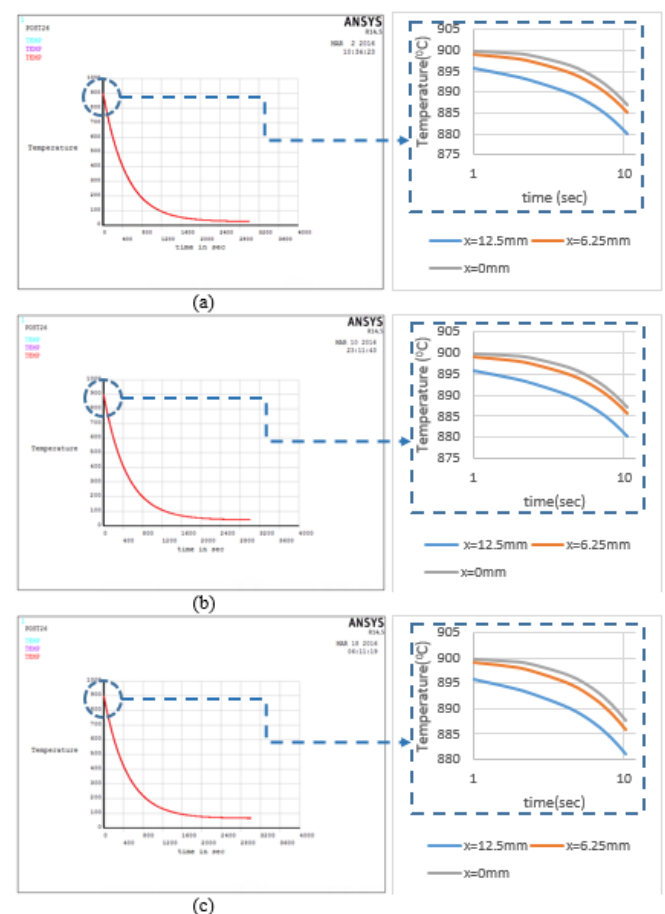

Gambar 11. Siklus Thermal cooling curve media pendingin gel aloe vera, (a) temperatur media pendingin $25^{\circ} \mathrm{C}$, (b) $45^{\circ} \mathrm{C}$, (c) $65^{\circ} \mathrm{C}$.

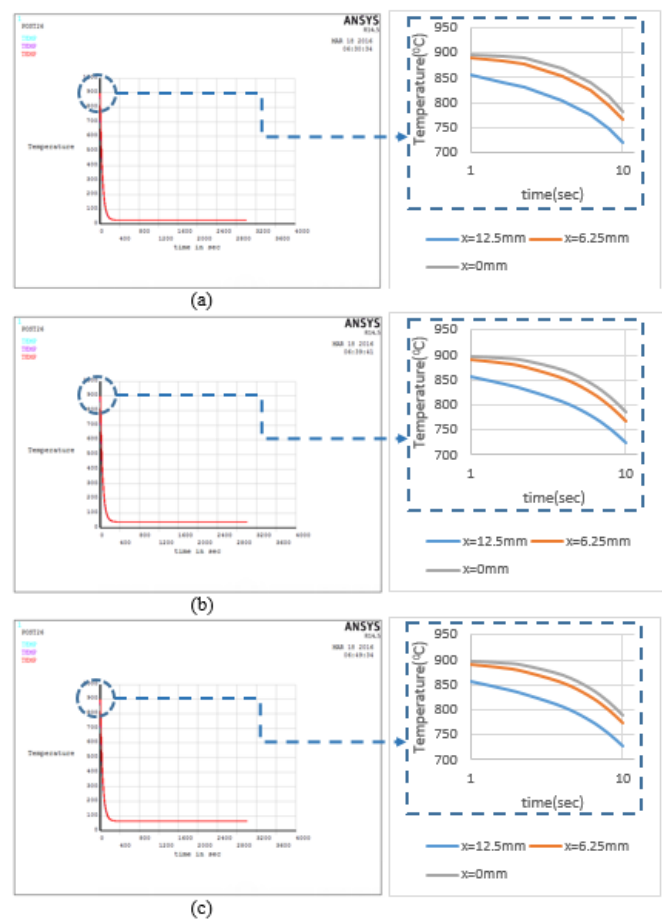

Gambar 12. Siklus Thermal cooling curve media pendingin air, (a) temperatur media pendingin $25^{\circ} \mathrm{C}$, (b) $45^{\circ} \mathrm{C}$, (c) $65^{\circ} \mathrm{C}$.
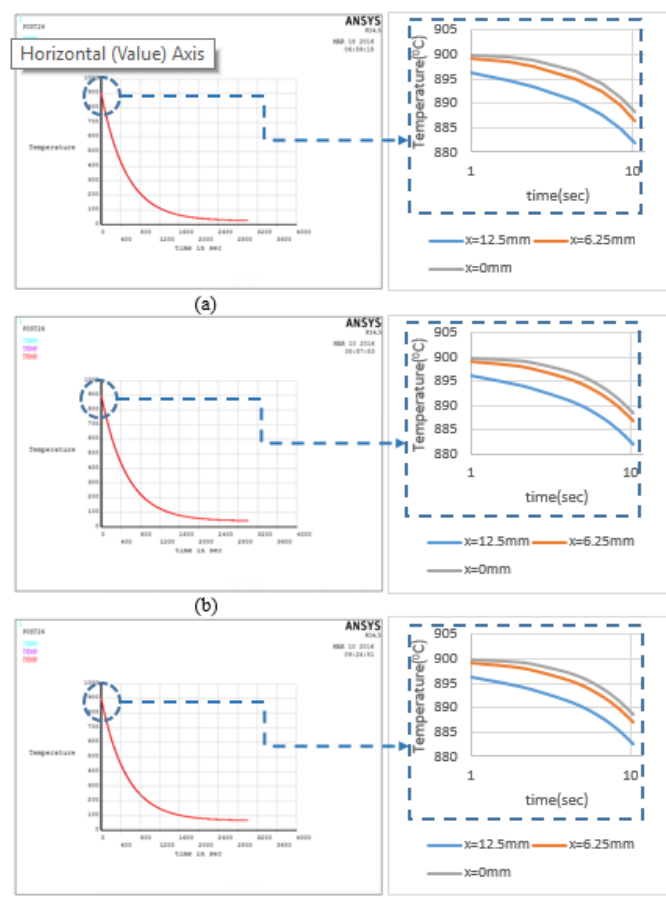

Gambar 13. Siklus Thermal cooling curve media pendingin oli, (a) temperatur media pendingin $25^{\circ} \mathrm{C}$, (b) $45^{\circ} \mathrm{C}$, (c) $65^{\circ} \mathrm{C}$.

Grafik siklus thermal cooling curve hasil simulasi pada proses quenching pada media pendingin gel aloe vera ditunjukkan pada Gambar 11. Sedangkan siklus thermal cooling curve hasil simulasi pada proses quenching pada media pendingin air ditunjukkan pada Gambar 12 dan siklus thermal cooling curve hasil simulasi pada proses quenching pada media pendingin oli ditunjukkan pada Gambar 13.

Proses quenching dengan media pendingin air mengalami penurunan temperatur yang lebih cepat meskipun dengan temperatur media pendingin yang berbeda. Hal ini sesuai dengan nilai convective coefficient air yang tinggi yaitu $741 \mathrm{Watt} / \mathrm{m}^{2} \mathrm{~K}$ sehingga panas pada spesimen akan cepat terserap oleh media pendingin. Sedangkan pada proses quenching dengan media pendingin oli dan gel aloe vera menunjukkan penurunan temperatur yang hampir sama dan tidak cepat seperti pada media pendingin air pada beberapa temperatur media pendingin yang berbeda. Hal ini dipengaruhi oleh nilai convective coefficient pada kedua media pendingin oli dan gel aloe vera yang sama-sama rendah dengan perbedaan yang tidak terlalu tinggi yakni 62 
Watt $/ \mathrm{m}^{2} . \mathrm{K}$ pada media pendingin oli dan 68 Watt $/ \mathrm{m}^{2}$.K pada media pendingin gel aloe vera.

Penurunan temperatur yang diGambarkan pada keseluruhan Gambar grafik diatas memberikan data untuk menghitung nilai cooling rate pada masing-masing variabel uji dimana nilai cooling rate dihitung dari perbandingan antara perubahan temperatur terhadap pertambahan waktu $(\Delta T / \Delta t)$. Grafik cooling rate pada masing-masing media pendingin secara keseluruhan ditunjukkan pada Gambar di bawah ini.

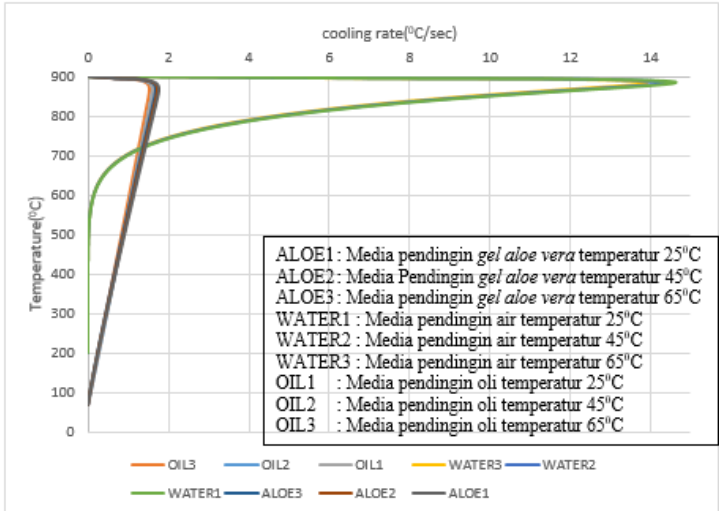

Gambar 14. Grafik cooling rate untuk media pendingin gel aloe vera, air, dan oli.

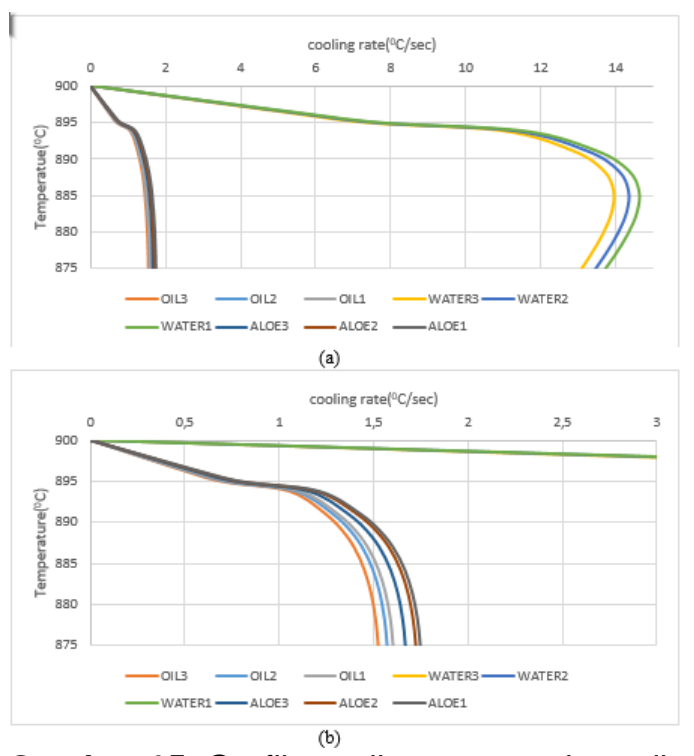

Gambar 15. Grafik cooling rate untuk media pendingin air (a), gel aloe vera dan oli (b).

Dari grafik cooling rate pada Gambar 14, menunjukkan bahwa nilai cooling rate pada media pendingin air lebih tinggi dibandingkan pada media pendingin gel aloe vera dan media pendingin oli dengan perbedaan nilai cooling rate yang cukup banyak. Sedangkan cooling rate pada media pendingin gel aloe vera memiliki nilai yang selalu mendekati nilai cooling rate pada media pendingin oli, meskipun nilai cooling rate pada media pendingin gel aloe vera lebih tinggi nilainya namun tidak menunjukkan perbedaan yang cukup berarti. Hal ini mengindikasikan bahwa logam yang diberikan proses quenching dengan media pendingin gel aloe vera akan memiliki nilai kekerasan, bentuk butir, dan jumlah martensite mendekati nilai pada hasil proses quenching logam dengan media pendingin oli. Sehingga bisa dikatakan bahwa gel aloe vera mempunyai peluang alternatif pengganti oli sebagai media pendingin pada proses quenching dengan kelebihan bahwa media pendingin gel aloe vera lebih ramah lingkungan dibandingkan dengan media pendingin oli.

Pada grafik yang ditunjukkan oleh Gambar 15. memberikan Gambaran bahwa temperatur media pendingin juga berpengaruh terhadap nilai cooling rate. Gambar 15. (a) menunjukkan bahwa proses quenching dengan media pendingin air dengan temperatur $25^{\circ} \mathrm{C}$ memiliki nilai cooling rate paling tinggi yang kemudian disusul dengan media pendingin air dengan temperatur $45^{\circ} \mathrm{C}$ dan kemudian media pendingin air dengan temperatur $65^{\circ} \mathrm{C}$. Gambar 15. (b) menunjukkan nilai cooling rate pada media pendingin gel aloe vera dan media pendingin oli. Nilai cooling rate yang paling tinggi diantara media pendingin gel aloe vera dan oli secara berurutan diberikan oleh proses quenching dengan media pendingin gel aloe vera dengan temperatur media pendingin $25^{\circ} \mathrm{C}$, $45^{\circ} \mathrm{C}$, dan $65^{\circ} \mathrm{C}$ yang kemudian disusul oleh proses quenching dengan media pendingin oli dengan temperatur media pendingin $25^{\circ} \mathrm{C}$, $45^{\circ} \mathrm{C}$, dan $65^{\circ} \mathrm{C}$.

Baja AISI 1045 merupakan baja paduan karbon rendah yang memiliki komposisi Carbon 0.42 sampai $0.50 \%$ dan Mangan 0.60 sampai $0.90 \%$ dengan nilai kekerasan $170 \mathrm{HVN}$. Setelah proses heat treatment yang dalam hal ini adalah proses hardening, logam mengalami peningkatan kekerasan. Pengambilan nilai kekerasan hanya pada spesimen uji proses hardening dengan metode quenching menggunakan gel aloe vera sebagai media 
pendingin dan temperatur media pendingin $25^{\circ} \mathrm{C}$ menggunakan Digital Microhardness Tester. Titik pengambilan nilai kekerasan difokuskan pada daerah permukaan logam (surface), titik pusat logam (center), dan diantara keduanya (between), setiap titik dilakukan 3 kali pengambilan data kemudian diambil nilai rata-rata. Nilai kekerasan hasil pengamatan ditunjukkan pada Tabel 3.

Tabel 3. Nilai kekerasan logam hasil quenching dengan media pendingin gel aloe vera.

\begin{tabular}{|c|c|c|c|c|}
\hline \multirow{2}{*}{ Xdistance } & \multicolumn{4}{|c|}{ Kekerasan (HVN) } \\
\cline { 2 - 5 } & Titik & Titik & Titik & Rata- \\
& 1 & 2 & 3 & rata \\
\hline $12.5 \mathrm{~mm}$ (Surfa & 198. & 187. & 182. & 189.6 \\
ce) & 6 & 7 & 6 & 3 \\
\hline $6.25 \mathrm{~mm}$ (Betw & 181. & 186. & 180. & 182.5 \\
een) & 1 & 2 & 4 & 66 \\
\hline Omm(Center) & 157. & 158. & 172. & 162.8 \\
& 0 & 7 & 9 & 66 \\
\hline
\end{tabular}

Dari Tabel 3, dapat memberikan informasi bahwa pada titik surface pada logam mengalami kenaikan kekerasaan menjadi 189.63 HVN dari nilai kekerasan awal 170 HVN, pada titik antara surface dan center juga mengalami kenaikan kekerasan menjadi 182.566 HVN dari nilai kekerasan awal 170 HVN, namun pada titik center mengalami penurunan menjadi 162.866 HVN dari nilai kekerasan awal 170 HVN. Kenaikan dan penurunan nilai kekerasan ini adalah pengaruh dari nilai cooling rate yang terjadi pada saat proses quenching berlangsung.

Selain kekerasan, proses hardening juga memberikan perubahan struktur mikro pada logam uji. Gambar di bawah menunjukkan Gambaran struktur mikro pada logam hasil proses hardening dengan media pendingin gel aloe vera. Pengambilan Gambar difokuskan pada 3 titik yakni pada titik surface, center, dan diantara keduanya. Pengamatan struktur mikro pada logam menggunakan foto mikro dengan perbesaran 400x.

Berdasarkan pengamatan struktur mikro logam (Gambar 16) hasil proses hardening menggunakan media pendingin gel aloe vera menunjukkan bahwa telah terjadi perubahan fasa dari austenite menjadi martensite pada daerah-daerah tertentu. Martensite mempunyai warna yang cenderung terang. Pada daerah surface memiliki jumlah martensite yang lebih banyak. Jumlah martensite semakin berkurang dan menjadi pearlite pada daerah sekitar diameter $x=9 \mathrm{~mm}$ kemudian berubah menjadi pearlite+bainite yang cenderung berwarna gelap pada daerah diameter $\mathrm{x}=0 \mathrm{~mm}$ sampai $x=5 \mathrm{~mm}$. Tabel di bawah ini menunjukkan data perubahan struktur mikro yang diamati pada spesimen dan dikomparasikan dengan titik nodal yang sesuai terhadap Xdistance pada spesimen.

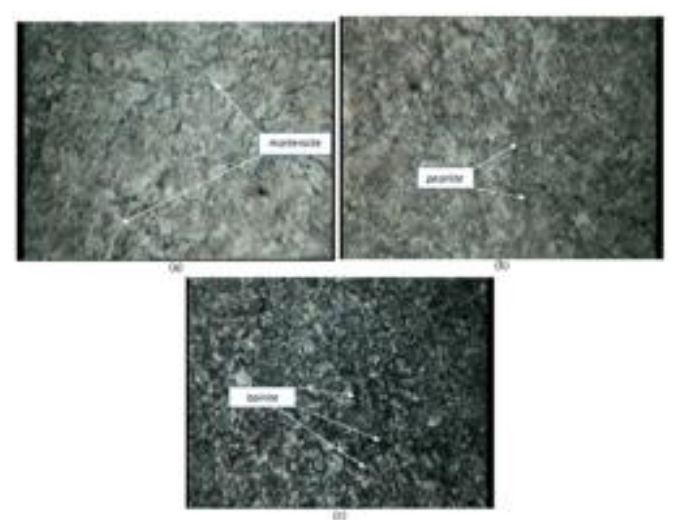

Gambar 16. Struktur mikro pada logam hasil hardening dengan media pendingin gel aloe vera. (a) Surface $(\mathrm{x}=12.5 \mathrm{~mm})$, (b) between surface and center ( $\mathrm{x}=6.25 \mathrm{~mm})$, (c) Center $(\mathrm{x}=0 \mathrm{~mm})$

Berdasarkan pengamatan struktur mikro logam hasil proses hardening menggunakan media pendingin gel aloe vera menunjukkan bahwa telah terjadi perubahan fasa dari austenite menjadi martensite pada daerahdaerah tertentu. Martensite mempunyai warna yang cenderung terang. Pada daerah surface memiliki jumlah martensite yang lebih banyak. Jumlah martensite semakin berkurang dan menjadi pearlite pada daerah sekitar diameter $\mathrm{x}=9 \mathrm{~mm}$ kemudian berubah menjadi pearlite+bainite yang cenderung berwarna gelap pada daerah diameter $\mathrm{x}=0 \mathrm{~mm}$ sampai $x=5 \mathrm{~mm}$. Tabel di bawah ini menunjukkan data perubahan struktur mikro yang diamati pada spesimen dan dikomparasikan dengan titik nodal yang sesuai terhadap $X_{\text {distance }}$ pada spesimen.

Penyebaran daerah-daerah yang mengalami perubahan struktur mikro dapat dilihat pada Gambar 17. 


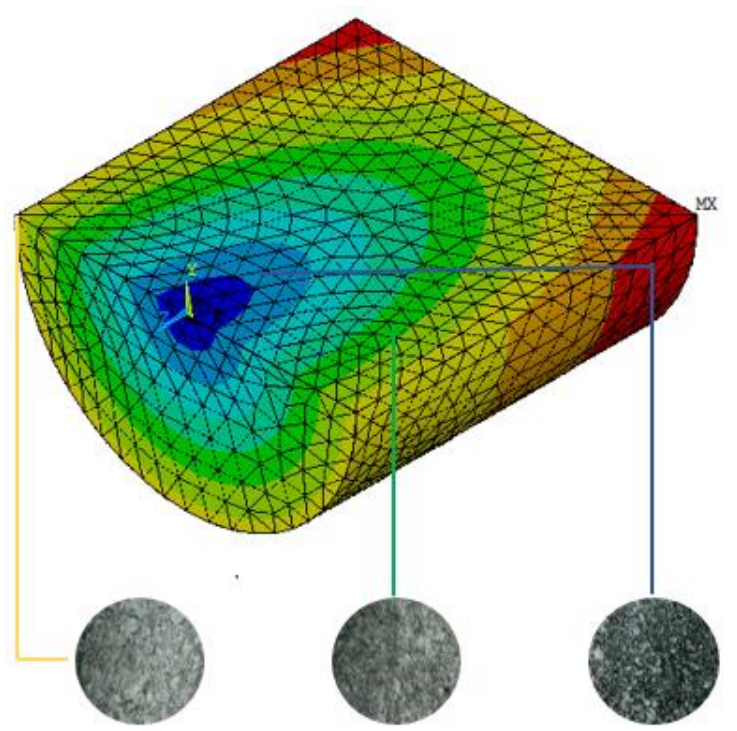

Gambar 17. Penyebaran daerah pembentukan struktur mikro pada spesimen uji

Dari Gambar di atas, diambil 3 buah titik yang paling dominan struktur mikronya berdasarkan pengamatan mikroskopis yaitu pada nodal 2 untuk struktur mikro martensite, nodal 533 untuk struktur mikro pearlite, dan nodal 14 untuk struktur mikro bainite. Penurunan temperatur pada nodal-nodal tersebut dikombinasikan terhadap diagram TTT (Time, Temperatur, dan Transformation) dan menghasilkan grafik yang ditunjukkan pada Gambar 18.

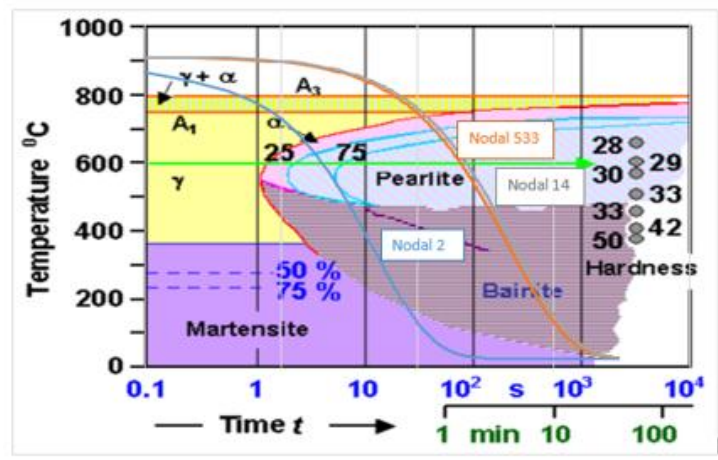

Gambar 18. Kurva penurunan temperatur terhadap diagram TTT.

Dari grafik dapat terlihat nilai penurunan temperatur terhadap perubahan fasa struktur mikro pada logam. Pada nodal 2 garis kurva berakhir pada daerah pembentukan fasa martensite, sedangkan garis kurva pada nodal
533 dan nodal 14 tidak melewati daerah pembentukan fasa martensite namun melewati daerah pembentukan fasa pearlite dan bainite.

Jumlah martensite berbeda akan menghasilkan nilai kekerasan logam yang berbeda di setiap titiknya. Semakin banyak jumlah martensite akan semakin tinggi nilai kekerasan pada logam tersebut. Begitupun sebaliknya, semakin berkurang jumlah martensite akan menghasilkan nilai kekerasan yang semakin menurun. Hal tersebut tentu telah dibuktikan dengan hasil uji kekerasan mikrovickers tersebut di atas.

\section{KESIMPULAN}

Dari hasil pengamatan didapatkan beberapa kesimpulan bahwa nilai cooling rate pada media pendingin air lebih tinggi dibandingkan pada media pendingin gel aloe vera dan media pendingin oli dengan perbedaan nilai cooling rate yang cukup tinggi. Sedangkan cooling rate pada media pendingin gel aloe vera memiliki nilai yang selalu mendekati nilai cooling rate pada media pendingin oli. Kesamaan nilai cooling rate memberikan hasil proses hardening yang sama pada logam, karena nilai cooling rate pada media pendingin gel aloe vera mendekati nilai cooling rate pada media pendingin oli maka bisa disimpulkan bahwa gel aloe vera mempunyai peluang alternatif pengganti oli sebagai media pendingin pada proses quenching dengan kelebihan bahwa media pendingin gel aloe vera lebih ramah lingkungan dibandingkan dengan media pendingin oli. Proses hardening menggunakan media pendingin gel aloe vera pada daerah surface memiliki jumlah martensite yang lebih banyak dibandingkan pada center dan diantara keduanya. Semakin banyak jumlah martensite akan semakin tinggi nilai kekerasan pada logam dan semakin sedikit jumlah martensite akan semakin rendah nilai kekerasan.

\section{DAFTAR PUSTAKA}

[1] Rusyanto, Edo. Proyeksi pasar 2014 2015 merujuk pada Asosiasi Industri Sepeda Motor Indonesia (AISI) dan Gabungan Industri Kendaraan Bermotor Indonesia (GAIKINDO). Viva.co.id. 7 agustus 2014.

[2] ASM International Metals HandBook. Volume 4 - Heat Treating. 
[3] Yang $X$., Jingchuan Zhu, Zhisheng Nong, Zhonghong Lai dan Dong He. 2013 FEM simulation of quenching process in A357 aluminum alloy cylindrical bars and reduction of quench residual stress through cold stretching process. Computational Materials Science 69 (2013) 396-413. 